\title{
Excited states dynamics in the ternary praseodymium and ytterbium/praseodymium halides
}

\author{
J. Legendziewicz ${ }^{\mathrm{a}, *}$, J. Cybińska ${ }^{\mathrm{a}}$, G. Boulon $^{\mathrm{b}}$, G. Meyer ${ }^{\mathrm{c}}$ \\ ${ }^{a}$ Institute of Chemistry, University of Wrockaw, Joliot-Curie 14, 50-383 Wrockaw, Poland \\ ${ }^{\mathrm{b}}$ Physics and Chemistry of Luminescent Materials, UMR 5620 CNRS, Claude BernardlLyon University, 69622 Villeurbane, France \\ ${ }^{\mathrm{c}}$ Institut für Anorganische Chemie, Universität zu Köln, Greinstrasse 6, D-50939 Köln, Germany
}

Received 10 March 2006; received in revised form 4 May 2006; accepted 8 May 2006

Available online 7 September 2006

\begin{abstract}
The purpose of this paper is investigation of the spectroscopic properties of $\mathrm{Pr}^{3+}$ and $\mathrm{Yb}^{3+} / \mathrm{Pr}^{3+}$ co-doped ternary lanthanum halides hosts in the form of powders and correlation of their optical behaviour with the appropriate crystals grown by the Bridgman method. Spectroscopic measurements relevant to laser applications, high resolution absorption and emission spectra at $293 \mathrm{~K}, 77 \mathrm{~K}$ and $4 \mathrm{~K}$ as well as emission decay times have been studied. The radiative transition probabilities were analyzed and Judd-Ofelt parameters in $\mathrm{K}_{2} \mathrm{LaCl}_{5}: 5 \% \mathrm{Pr}^{3+}$ were calculated. A drastic enhancement of the intensities in the powdered halides has been observed as compared to the single crystal spectra. An up-conversion emission has been detected and the observed phenomena are discussed.

(C) 2006 Elsevier B.V. All rights reserved.
\end{abstract}

\section{Introduction}

The development of new luminescent materials and progress in their studies depend on our understanding of physical processes in solids. The most suitable materials are large band gap inorganic lattices activated by rare earth ions. Optical excitations in these systems result either in a direct excitation of the luminescence center or in an excitation of the host lattice which partially transfers this energy to the emitting states of the activator [1-8].

Establishing of the mechanism of the energy transfer and the energy losses is usually possible using different energies of the excitation and the decay time measurements. New technologies are emerging emloying rare earth activators with the VUV and XUV excitation energy ranges.

Isolators are important both in medical applications as fast scintillators with high light yields and for color centers plasma display panels as well as ultraviolet tunable solid

\footnotetext{
* Corresponding author.

E-mail address: j1@wchuwr.chem.uni.wroc.pl (J. Legendziewicz).
}

state lasers. A lot of fluoride and oxide crystals have been investigated for their scintillation properties and new phosphors, mainly codoped by $\mathrm{Ce}(\mathrm{III})$ and $\operatorname{Pr}(\mathrm{III})$ ions in different crystalline hosts, exhibit intense broad band emission due to the parity allowed electric dipol $4 \mathrm{f}^{N-1} 5 \mathrm{~d}^{1} \rightarrow 4 \mathrm{f}^{N}$ transitions $(N=1$ and 2 , respectively). Their decay times are about $10-50 \mathrm{~ns}$. Thus they are good candidates both for ultraviolet tunable solid state lasers and for fast scintillator devices [1-8]. The $\mathrm{K}_{2} \mathrm{LaX}_{5}$ host is promising in this regard both as single crystals and powdered samples. Also, the small separations of the neighboring active ions and the formation of the polymeric chains in the structure make this type of crystals very interesting due to the cooperative interactions. It is important to note that the phonons frequencies of the oxides materials are much higher and the multiphonon relaxation processes are more efficient than in the halides [9-12]. We have reported recently the spectroscopic and simulation results of the crystal field effects as well as the paramagnetic behaviour of $\mathrm{K}_{2}(\mathrm{La}, \mathrm{Pr}) \mathrm{X}_{5}$ $\left(\mathrm{X}=\mathrm{Cl}^{-}, \mathrm{Br}^{-}\right)$ternary halides $[13,14]$. The excited states dynamics has been also investigated by us [15-17]. In this work the electron and vibronic transition probabilities 
and decay times as well as the up-conversion emission will be presented. The comparison will be made of the radiative transitions probabilities between the crystals and the powdered systems, which is critically important for powder laser applications. Employment of different excitation sources $(\gamma$ - and X-ray irradiation, 308 and $355 \mathrm{~nm}$ laser lines with different powers) has shown that the crystals under investigation are very sensitive to the energy of the excitation and can help in understanding of the radiative and non-radiative processes in the system under investigation. Some features in the upconversion fluorescence vary in the series of halides $(\mathrm{Cl}, \mathrm{Br}, \mathrm{I})$. The non-radiative energy transfers between the $\operatorname{Pr}^{3+}$ ions and the $\operatorname{Pr}^{3+}$ $\mathrm{Yb}^{3+}$ ions have been observed and the up-conversion mechanisms will be proposed.

\section{Experimental}

The monocrystals of $\mathrm{K}_{2}(\mathrm{La}, \mathrm{Ln}) \mathrm{X}_{5}\left(\mathrm{Ln}=\mathrm{Pr}^{3+}, \mathrm{Yb}^{3+}\right)$ ternary halides with wide ranges of the active ions concentrations were obtained by the method described previously $[17,18]$ via the Bridgman technique. X-ray diffraction was used to check the purity and structure of the samples especially in the powered systems. ICP ES was used to control the concentrations of the active ions and the impurities in the investigated crystals. The synthetic conditions for all the synthesized ternary halides are given in Table 1 .

\subsection{Spectroscopic measurements}

Crystals were selected, cut and polished in a nitrogen dry box to a thickness required for the absorption measurements. They were closed between two quartz windows to protect them from moisture. A special prepared quartz tube was used to detect the emission spectra at 77 and $4 \mathrm{~K}$.

The absorption spectra were recorded at 4 and $293 \mathrm{~K}$ with a Carry-Varian 500 Scan spectrometer equipped with an Oxford helium flow cryostat in the 200-25000 nm spectral range. Spectra of the solid $\operatorname{Pr}($ III) ternary halide were obtained from the powder placed between two quartz windows in the UV region and from the crystal, also closed between two quartz plates, in the VIS and IR ranges. The halides in the powered forms were prepared as tablets under the pressure of $7 \mathrm{~atm}$ and used for the absorption measurements. The intensities of the $\mathrm{f}-\mathrm{f}$ transitions were calculated by integration of an Gauss-Lorenz curve and transformed to the oscillator strengths values. The luminescence decay time measurements were performed using a Continuum OPO Surelite I (line $460 \mathrm{~nm}$ or $588 \mathrm{~nm}, 8 \mathrm{~ns}$ pulse) pumped by the third harmonic of a Nd-YAG laser $(355 \mathrm{~nm})$ and the $308 \mathrm{~nm}$ excimer laser line to determine the decay times of the emission in different spectral regions.

The emission spectra were obtained on an Action Research Corporation Spectra Pro 750 monochromator equipped with a Hamamatsu R 928 photomultiplier as the detector (resolution $0.01 \mathrm{~nm}$ ) for comparison of the ternary chloride and bromide emission properties. The VUV behaviour of the chloride and bromide lattices was checked by the UV excitation spectra of the ${ }^{3} \mathrm{P}_{0} \rightarrow{ }^{3} \mathrm{H}_{4}$ emission (at $394 \mathrm{~nm})$ and the excitation emissions $\left(\lambda_{\operatorname{det}} 390-420\right.$ and $600-900 \mathrm{~nm}$ ) between 10 and $300 \mathrm{~nm}$ as well as the respective emission spectra obtained by synchrotron radiation (DESY synchrotron, Hamburg Synchrotron Radiation Laboratory HASYLAB, Germany).

\section{Results and discussion}

The $\mathrm{K}_{2} \mathrm{LaCl}_{5}$ crystallizes in the orthorhombic centrosymmetric space group Pnma- $D_{2 \mathrm{~h}}^{16}(\# 62, Z=4)$ with the lattice constants $a=12.742$ (3), $b=8.868$ (3), and $c=$ 8.022 (2) $\AA$ [18]. It has been checked by the X-ray powder diffraction that doping the host matrices by the active ions does not change the structure. All the lanthanide halides of the $\mathrm{K}_{2} \mathrm{La}, \mathrm{LnX} \mathrm{X}_{5}$ type are isostructural with the ternary praseodymium chloride [19].

The crystal structure of $\mathrm{K}_{2} \mathrm{LaCl}_{5}$ consists of $\mathrm{LaCl}_{7}$ polyhedra connected by the two common edges to form infinite chains running along the crystallographic $b$ axis. The details of structures are described in [19]. The spectroscopic properties are affected by the relatively short intra-chain Ln-Ln distances $(\sim 4.5 \AA)$, which can promote the cooperative ion-ion interactions.

Complex absorption spectra at the room and liquid helium temperatures for $\mathrm{K}_{2} \mathrm{LaCl}_{5}: 5 \% \mathrm{Pr}^{3+}$ as well as for $\mathrm{K}_{2} \mathrm{LaCl}_{5}: 5 \% \mathrm{Pr}^{3+}: 2 \% \mathrm{Yb}^{3+}$ can be expected. Figs. 1 and 2 show the UV and VIS absorption spectra for both crystals as well as the spectra in the same range for the powdered samples.

The absorption spectra of $\mathrm{K}_{2}(\mathrm{La}, \mathrm{Pr}) \mathrm{Cl}_{5}$ between 435 and $2000 \mathrm{~nm}$ comprise of the transitions from the ground ${ }^{3} \mathrm{H}_{4}$ state to the excited ${ }^{3} \mathrm{~F}_{2-4},{ }^{1} \mathrm{G}_{4},{ }^{1} \mathrm{D}_{2},{ }^{3} \mathrm{P}_{0-2}$, and ${ }^{1} \mathrm{I}_{6}$ levels. Additionally, the ${ }^{2} \mathrm{~F}_{7 / 2} \rightarrow{ }^{2} \mathrm{~F}_{5 / 2}$ transition for the crystals codoped with $\mathrm{Yb}^{3+}$ in the range $920-980 \mathrm{~nm}$ is observed. In the VIS region all the $\operatorname{Pr}^{3+}$ ion transitions in the $\mathrm{K}_{2} \mathrm{LaCl}_{5}: 5 \% \mathrm{Pr}^{3+}$ crystals spectra are red shifted in comparison with the respective transitions observed for the $\mathrm{Yb}^{3+}$ codoped systems (Fig. 2). The absorption spectra of the diluted crystals are not so complex as the stoichiometric

Table 1

The conditions of ternary halides synthesis

\begin{tabular}{llllll}
\hline & Starting temperature $\left({ }^{\circ} \mathrm{C}\right)$ & Cooling rate $\left({ }^{\circ} \mathrm{C} / \mathrm{h}\right)$ & Till temperature $\left({ }^{\circ} \mathrm{C}\right)$ & Cooling rate $\left({ }^{\circ} \mathrm{C} / \mathrm{h}\right)$ & End temperature $\left({ }^{\circ} \mathrm{C}\right)$ \\
\hline $\mathrm{K}_{2} \mathrm{PrCl}_{5}$ & 640 & 1 & 470 & 5 & 20 \\
$\mathrm{~K}_{2} \mathrm{Pr}_{X} \mathrm{La}_{1-x} \mathrm{Cl}_{5}$ & 900 & 1 & 700 & 5 & 20 \\
$\mathrm{~K}_{2} \mathrm{Yb}_{X} \mathrm{La}_{1-x} \mathrm{Cl}_{5}$ & 900 & 1 & 700 & 5 & 20 \\
\hline
\end{tabular}




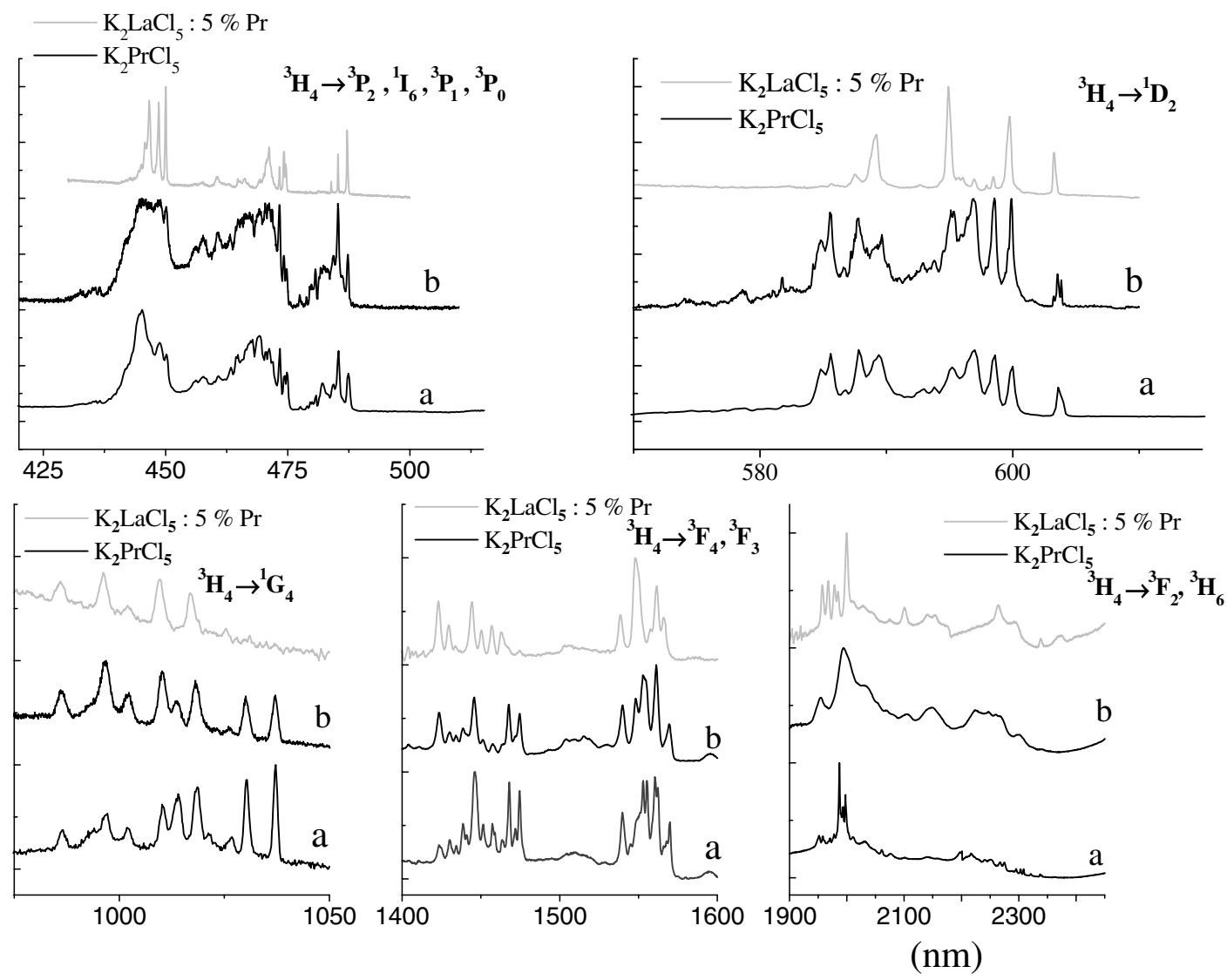

Fig. 1. Absorption spectra of $\mathrm{K}_{2} \mathrm{PrCl}_{5}\left(a\right.$ - powder sample, $b$ - single crystal) and $\mathrm{K}_{2} \mathrm{LaCl}_{5}: \mathrm{Pr}^{3+}$ at $4 \mathrm{~K}$.

single crystals spectra (see Fig. 1). It confirms the strong ionion interactions in the pairs of the components appearing in the systems under investigations. The complex structure of the bands also results from the strong electron-phonon coupling, mainly in the bromide and iodide matrices (Fig. 3).

\section{Intensity analysis}

The lasing behaviour of the powdered samples depends strongly on the radiative transition probabilities and also on the various emission quenching phenomena. The small influence of temperature on the emission efficiency of the $\mathrm{K}_{2} \mathrm{PrCl}_{5}$ crystal has been shown in our previous reports. The concentration affects strongly the emission efficiency in all the investigated systems. Since we have observed previously an increase of the $\mathrm{f}-\mathrm{f}$ transition intensity in the powdered systems, thus an effort has been made to establish the differences between the radiative transitions probabilities between the crystals and the powdered samples.

The absorption spectra of $\operatorname{Pr}^{3+}$ in the visible and IR regions involve the parity forbidden $4 \mathrm{f}-4 \mathrm{f}$ transitions from the ${ }^{3} \mathrm{H}_{4}$ ground state to the various excited ${ }^{3} \mathrm{H}_{\mathrm{J}},{ }^{3} \mathrm{~F}_{\mathrm{J}},{ }^{3} \mathrm{P}_{\mathrm{J}}$ and ${ }^{1} \mathrm{I}_{\mathrm{J}},{ }^{1} \mathrm{D}_{2}$ levels. The oscillator strength values have been calculated and are listed in Table 2. The oscillator strength values have been calculated on the basis of the real $\operatorname{Pr}^{3+}$ concentrations determined by the ICP method and are shown for the crystals and the powders. The drastic differ- ences in the values of the oscillator strengths for the crystals and the tablets with the same concentrations of the active $\operatorname{Pr}^{3+}$ ions can be seen. This could be caused by nanostructural effects.

Moreover, the significant differences have been also observed for the intensities of the appropriate transitions in the two types of the crystals: $\mathrm{K}_{2} \mathrm{LaCl}_{5}: 5 \% \mathrm{Pr}^{3+}$ and $\mathrm{K}_{2} \mathrm{LaCl}_{5}: 5 \% \mathrm{Pr}^{3+}: 2 \% \mathrm{Yb}^{3+}$ with the same concentrations of the $\mathrm{Pr}^{3+}$ ions. The Judd-Ofelt relation in the form given by Carnall [20] has been used to calculate the $\tau_{\lambda}$ parameters.

$P=\sum_{\lambda=2,4,6} \tau_{\lambda} \sigma\left(f^{n} \psi J\left\|U^{(\lambda)}\right\| f^{n} \psi^{\prime} J^{\prime}\right)^{2} /(2 J+1)$

where $\left\langle f^{n} \psi J\left\|U^{(\lambda)}\right\| f^{n} \psi^{\prime} J^{\prime}\right\rangle$ are the reduced matrix elements of the unit tensor operator $U^{(\lambda)}$ between the initial $\psi_{\mathrm{J}}$ and the final $\psi^{\prime} J^{\prime}$ levels.

The transitions which obey the $\Delta J= \pm 2, \Delta L= \pm 2$ selection rules are the most sensitive to the structural changes and have usually the highest oscillator strength values. For the $\mathrm{Pr}^{3+}$ ion, the ${ }^{3} \mathrm{H}_{4} \rightarrow{ }^{3} \mathrm{P}_{2}$ transition (although it does not satisfy both rules required for hypersensitivity) has the larger oscillator strength. The theory of the electric dipole $\mathrm{f}-\mathrm{f}$ transitions for the $\mathrm{Pr}^{3+}$ systems poses a special problem due to the mean energy dominator $(\Delta E)$ in the frame of the Judd-Ofelt intensity formalism. This exceptional behaviour of $\mathrm{Pr}^{3+}$ leads to difficulties in appli- 

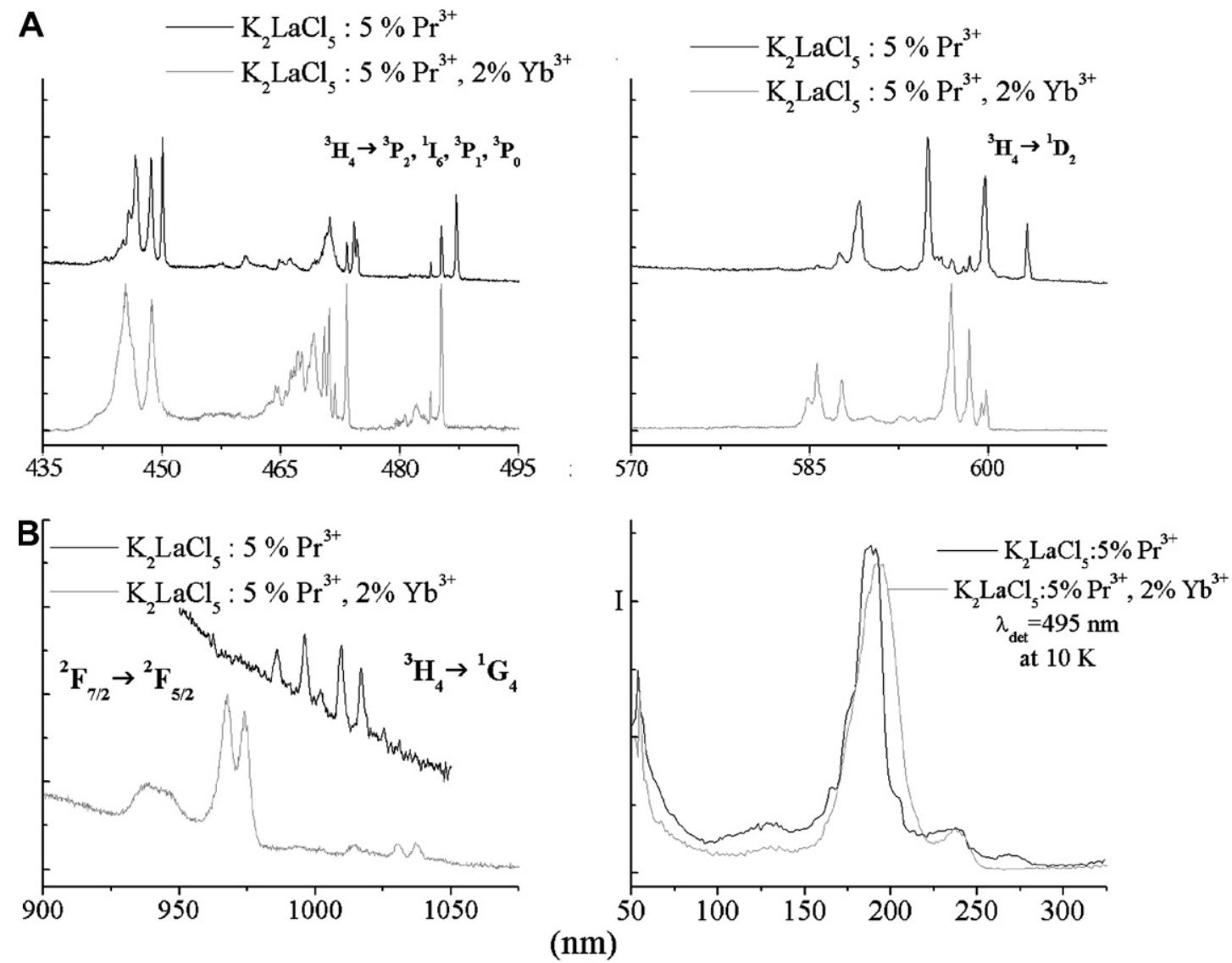

Fig. 2. Absorption spectra of $\mathrm{K}_{2} \mathrm{LaCl}_{5}: \mathrm{Pr}^{3+}$ and $\mathrm{K}_{2} \mathrm{LaCl}_{5}: \mathrm{Pr}^{3+}, 2 \% \mathrm{Yb}^{3+}$ at $4 \mathrm{~K}(\mathrm{~A})$ and the UV and VUV synchrotron excitation spectra of the ${ }^{3} \mathrm{P}_{0} \rightarrow$ ${ }^{3} \mathrm{H}_{4}$ emission (495 nm) (B).

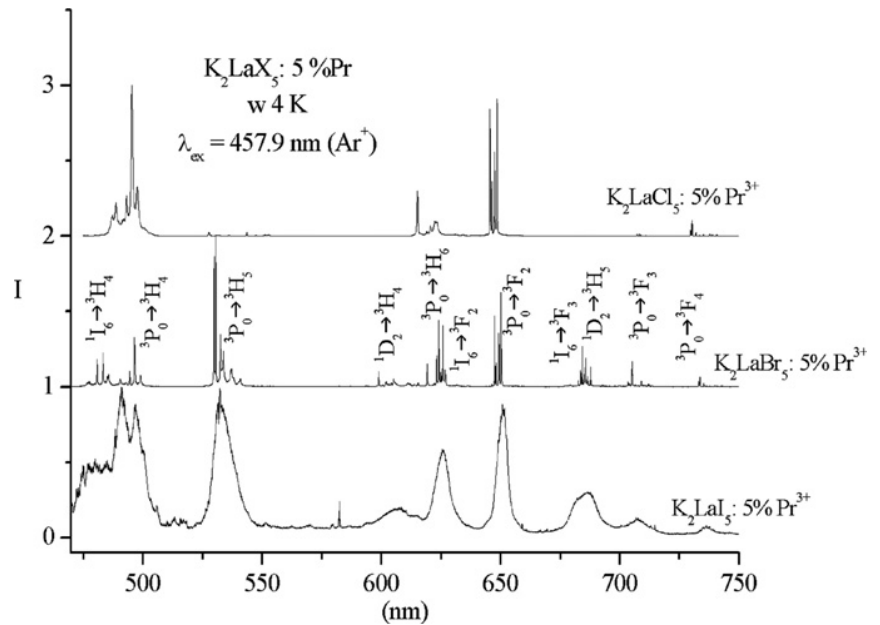

Fig. 3. The emission spectra of $\mathrm{K}_{2}\left(\mathrm{La}_{0.95} \mathrm{Pr}_{0.05}\right) \mathrm{X}_{5}$, measured under $\mathrm{Ar}^{+}$ ion laser excitation $(\lambda=457.9 \mathrm{~nm})$ at $4 \mathrm{~K}$.

cation of the theory and determination of the phenomenological $\tau_{\lambda}$ parameters calculated from the set of the experimental oscillator strength values. It is worth noting that in the calculations presented here for $\mathrm{K}_{2} \mathrm{LaCl}_{5}: 5 \% \mathrm{Pr}^{3+}$ the $\tau_{\lambda}$ parameters have been obtained with the low estimations errors only when the ${ }^{3} \mathrm{~F}_{2},{ }^{1} \mathrm{D}_{2},{ }^{3} \mathrm{P}_{0},{ }^{3} \mathrm{P}_{1},{ }^{1} \mathrm{I}_{6}$ and ${ }^{3} \mathrm{P}_{2}$ bands intensities have been used and the ${ }^{3} \mathrm{H}_{4} \rightarrow{ }^{3} \mathrm{~F}_{3}$ and
${ }^{3} \mathrm{H}_{4} \rightarrow{ }^{3} \mathrm{~F}_{4}$ transitions have been eliminated. Those last two transitions are mainly of the magnetic dipole origin and the pronounced values of these intensities are due to that mechanism. Moreover, since the ${ }^{3} \mathrm{H}_{4} \rightarrow{ }^{3} \mathrm{~F}_{2}$ transition is truly hypersensitive, its exclusion from the calculation leads to the $\tau_{\lambda}$ parameters negative values with no physical sense. In fact, the $U^{(\lambda)}$ matrix elements of ${ }^{3} \mathrm{~F}_{2}$ are the largest $(0.5089,0.4032,0.1177)$ so when the ${ }^{3} \mathrm{H}_{4} \rightarrow{ }^{3} \mathrm{~F}_{2}$ transition is taken into account in the intensity calculations a much better estimation is obtained, especially for the $\tau_{2}$ parameter (analogously to the data reported by us in Refs. [2123]).

However, this transition is not easily seen in the absorption spectra because it occurs in the 1800-2000 nm region and is usual overlapped by the IR-active transitions of the lattice. The discussion of the results presented in [24] is not acceptable because the net intensity can be evaluated by the comparative measurements of the $\mathrm{Pr}^{3+}$ crystal versus the isotypic single crystals of the lanthanum compound, as it has been discussed by us [22].

It should be noted that the dilution of the crystals does not lead to the same concentration of the active ions as the procedure implies. This conclusion comes from the comparison of the number of the cooperative components in the low temperature spectra of the ternary praseodymium 


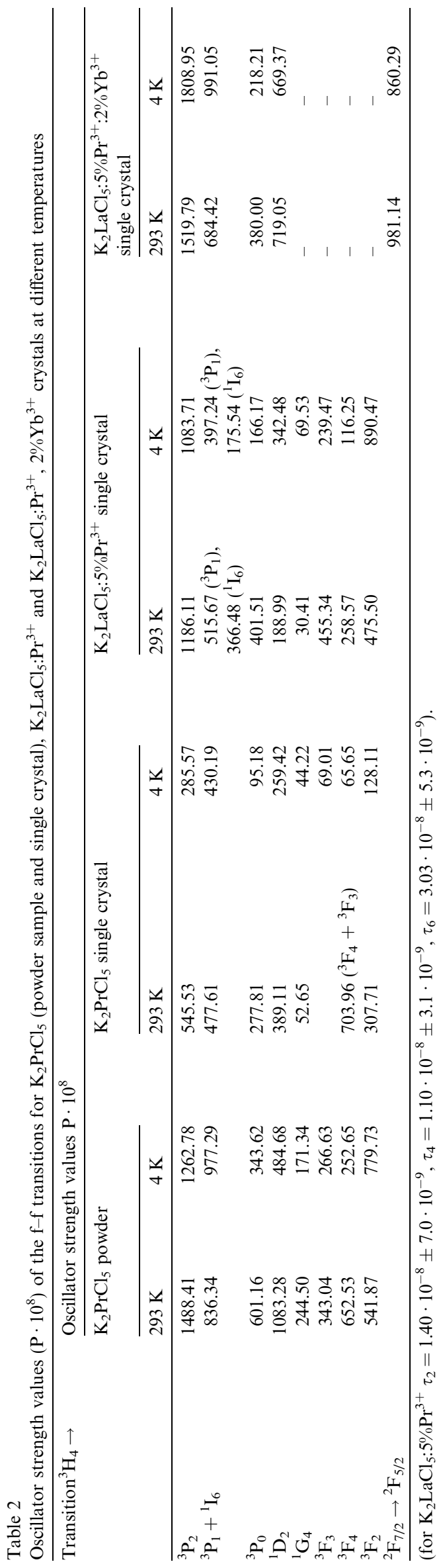

chloride and bromide. Thus detection of the real concentrations in the samples is critical important.

On the other hand, the studies of the effect of the cooperative interactions on the $\mathrm{f}-\mathrm{f}$ transitions intensities seem to be important. We have published recently the results of the intensity analysis for lanthanide bromides, molibdates and a tungstanate $(0.01-1 \mathrm{~mol} / \%$ concentration $)$ as well as for the series of the dimer lantanide single crystals with aminoacids $[25,26]$. The nonlinear relationship of the intensities versus the concentration has been found [25]. Moreover, a decrease of the intensities with an increase of the concentrations has been detected for some transitions [26]. Since the ${ }^{3} \mathrm{H}_{4} \rightarrow{ }^{1} \mathrm{D}_{2}$ and ${ }^{3} \mathrm{~F}_{4}$ and ${ }^{3} \mathrm{~F}_{3}$ transitions are separated well from the other ones this effect will be studied for such transitions mainly in the $0.05-1.00 \mathrm{~mol} / \%$ concentration range. The results of the calculations for the ternary chlorides are collected in Table 2. In the same Table the results of the intensity calculations at $4 \mathrm{~K}$ are included also. The irregular intensity changes with the concentration (mainly for the ${ }^{1} \mathrm{D}_{2}$ transition) are observed. The variation in the intensities changes with the temperature decrease can also be detected. Since a decrease of temperature leads finally to the depopulation of the ${ }^{3} \mathrm{H}_{4}$ ground state multiplet, thus it could be accompanied by the decrease of the intensities. In fact, we have observed a decrease of the intensities for some transitions but the increase has been observed for ${ }^{3} \mathrm{H}_{4} \rightarrow{ }^{1} \mathrm{D}_{2},{ }^{1} \mathrm{G}_{4}$ showing a quite opposite relationship to that found for the fully concentrated crystals.

Unexpectedly high oscillator strength values in the spectra of the $\mathrm{K}_{2} \mathrm{LaCl}_{5}: 5 \% \mathrm{Pr}^{3+}: 2 \% \mathrm{Yb}^{3+}$ crystal can be noted, also. The $\mathrm{f}-\mathrm{f}$ transition intensities for the crystals with the same concentration of the active ions should be similar, providing the structure is not distorted. A completely different behaviour has been observed in our case. This difference could suggest that in the crystals codoped with the $\mathrm{Yb}^{3+}$ ions pair $\mathrm{Pr}^{3+}$ ions interaction becomes less efficient and/or some sub-lattices are created in the structure. This hypothesis needs additional studies of the crystals with the different concentrations of the $\operatorname{Pr}^{3+}: \mathrm{Yb}^{3+}$ active ions.

\subsection{Decay times}

The decay times of the ${ }^{3} \mathrm{P}_{0}$ emission at 293 and $77 \mathrm{~K}$ are displayed in Fig. 4a and Table 3. The temperature and concentration dependencies of the decay times are observed (see Fig. 4 and Table 3). The decay times are mainly monoexponential functions.

The decay time of the fully concentrated ternary chloride crystals is very short and equal $126 \mathrm{~ns}$ [17]. A decrease of the temperature leads to an increase of the decay times but they are still short and equal $10.5 \mu$ s for the $5 \mathrm{~mol} / \%$ sample at $77 \mathrm{~K}$. The decay curve is purely exponential for the ${ }^{3} \mathrm{P}_{0}$ emission and the determined $\tau$ increases drastically to $3.4 \mu$ s for the fully concentrated crystals at $77 \mathrm{~K}$. The decay times at $293 \mathrm{~K}$ increase with the concentration decrease from 1.26 to $10.5 \mu$ s for the $5 \mathrm{~mol} / \%$ crystal (see Table 3). It could suggest that the cross-relaxation process 

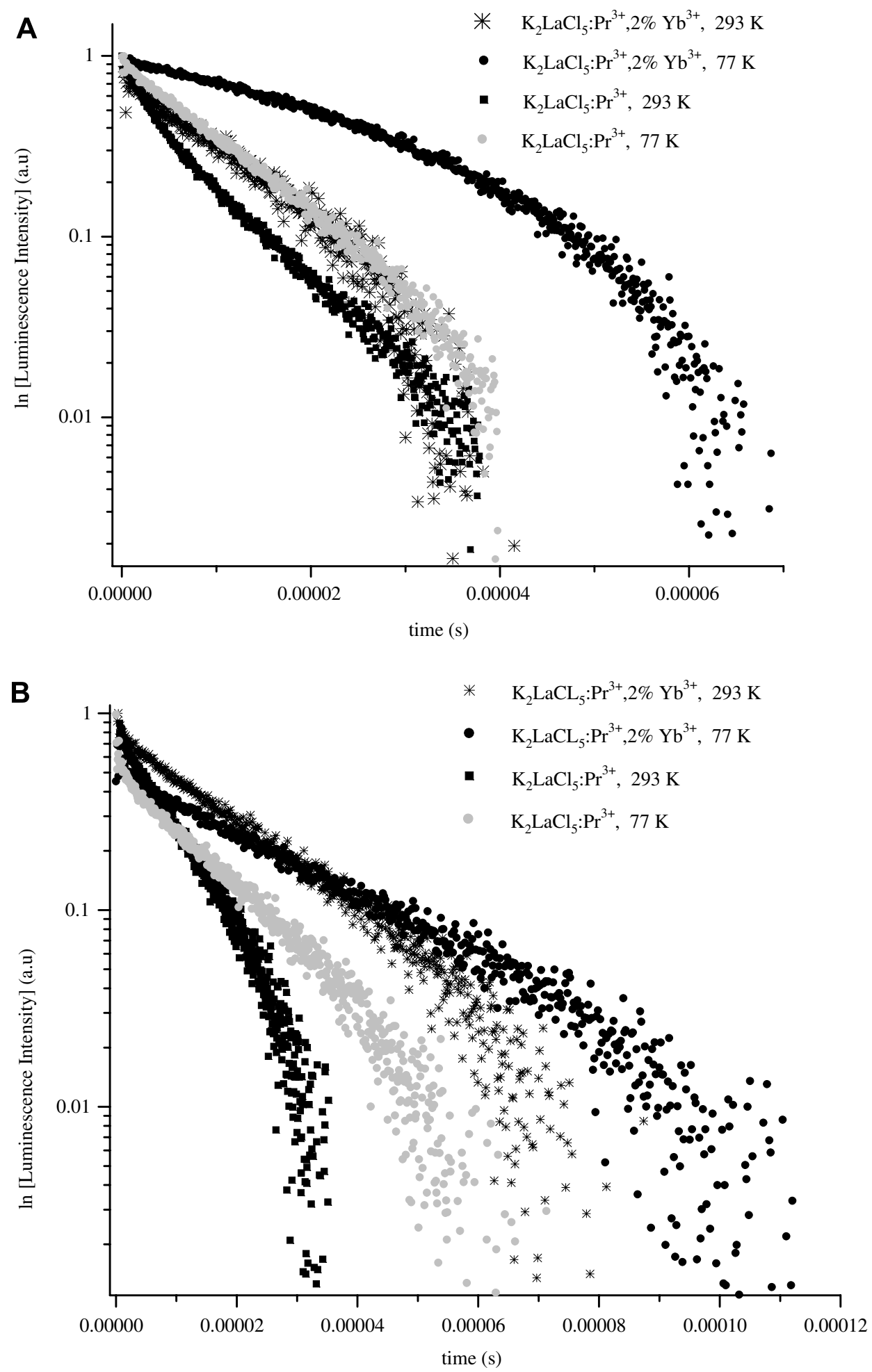

Fig. 4. Decay curves of the luminescence recorded for $\mathrm{K}_{2} \mathrm{LaCl}_{5}: \mathrm{Pr}^{3+}$ and $\mathrm{K}_{2} \mathrm{LaCl}_{5}: \mathrm{Pr}^{3+}, 2 \% \mathrm{Yb}^{3+}$ crystals upon ${ }^{3} \mathrm{P}_{0}(\mathrm{~A})$ and ${ }^{1} \mathrm{D}_{2}$ (B) excitation at 293 and $77 \mathrm{~K}$.

takes place for the ${ }^{3} \mathrm{P}_{0} \rightarrow{ }^{3} \mathrm{H}_{6},{ }^{3} \mathrm{~F}_{3}$ emission but it is less effective than for the ${ }^{1} \mathrm{D}_{2}$ emission. This deexcitation process is phonon-assisted. The decay times for the ${ }^{1} \mathrm{D}_{2}$ emission are little longer and equal $15 \mu$ at $77 \mathrm{~K}$ for the diluted crystals. The decay times for the $\mathrm{Yb}^{3+}$-codoped crystals are longer for the ${ }^{3} \mathrm{P}_{0}$ emission as well as for the ${ }^{1} \mathrm{D}_{2}$ emission. Moreover, they are not monoexponential functions. It suggests the less efficient cross-relaxation process in the case of the $\mathrm{K}_{2} \mathrm{LaCl}_{5}: 5 \% \mathrm{Pr}^{3+}, 2 \% \mathrm{Yb}^{3+}$ crystals emission. It is worth noting that the decay times for the $1.00 \mathrm{~mol} / \%$ crystals are 
Table 3

The decay times of the luminescence recorded for $\mathrm{K}_{2} \mathrm{LaCl}_{5}: \mathrm{Pr}^{3+}$ and $\mathrm{K}_{2} \mathrm{LaCl}_{5}: \mathrm{Pr}^{3+}, 2 \% \mathrm{Yb}^{3+}$ crystals and $\mathrm{K}_{2} \mathrm{PrCl}_{5}$ powder upon ${ }^{3} \mathrm{P}_{0}$ and ${ }^{1} \mathrm{D}_{2}$ excitation at 293 and $77 \mathrm{~K}$

\begin{tabular}{rlllll}
\hline & $\mathrm{K}_{2} \mathrm{PrCl}_{5}{ }^{3} \mathrm{P}_{0}(\mu \mathrm{s})$ & $\mathrm{K}_{2} \mathrm{LaCl}_{5}:$ & $\mathrm{K}_{2} \mathrm{LaCl}_{5}:$ & $\mathrm{K}_{2} \mathrm{LaCl}_{5}:$ & $\mathrm{K}_{2} \mathrm{LaCl}_{5}:$ \\
& $5 \% \mathrm{Pr}^{3+}{ }^{3} \mathrm{P}_{0}(\mu \mathrm{s})$ & $5 \% \mathrm{Pr}^{3+1} \mathrm{D}_{2}(\mu \mathrm{s})$ & $5 \% \mathrm{Pr}^{3+}, 2 \% \mathrm{Yb}^{3+}{ }^{3} \mathrm{P}_{0}(\mu \mathrm{s})$ & $5 \% \mathrm{Pr}^{3+}, 2 \% \mathrm{Yb}^{3+1} \mathrm{D}_{2}(\mu \mathrm{s})$ \\
\hline 293 & 0.126 & 5.8 & 10.9 & 15.0 & 18.7 \\
77 & 3.4 & 10.5 & 14.8 & 32.3 & 30.6 \\
\hline
\end{tabular}

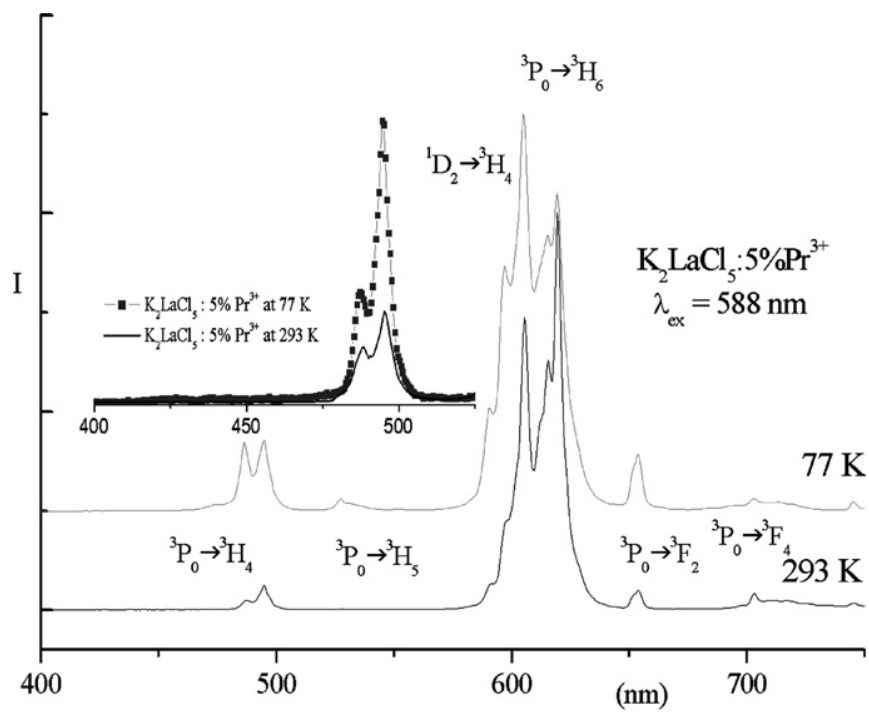

Fig. 5. The emission spectra of $\mathrm{K}_{2} \mathrm{LaCl}_{5}: \% 5 \mathrm{Pr}^{3+}$ under $588 \mathrm{~nm}$ pumping at 77 and $293 \mathrm{~K}$.

on the same order of the magnitude as for $\mathrm{MPrP}_{4} \mathrm{O}_{12}$ $(\mathrm{M}=\mathrm{Rb}$ and $\mathrm{Cs})$ reported earlier by Gâcon et al [27]. The decay times for the diluted single crystals are comparable to those reported by Meijerink et al [8] for the Pr (III) doped $\mathrm{CdBr}_{3}^{-}$lattice.

The crystals of $\mathrm{K}_{2} \mathrm{LaCl}_{5}: 5 \% \mathrm{Pr}^{3+}: 2 \% \mathrm{Yb}^{3+}$ as well as $\mathrm{K}_{2} \mathrm{LaCl}_{5}: 5 \% \mathrm{Pr}^{3+}$ show the upconversion emission (see Fig. 5 and also Figs. 10 and 11 in Ref. [15]). In the emission spectra of $\mathrm{K}_{2} \mathrm{LaCl}_{5}: 5 \% \mathrm{Pr}^{3+}$ under the excitation to the ${ }^{1} \mathrm{D}_{2}$ level $(588 \mathrm{~nm})$ one can observe the emission from the ${ }^{3} \mathrm{P}_{0}$ level, besides the resonance emission from the ${ }^{1} \mathrm{D}_{2}$ state, whereas the $940 \mathrm{~nm}$ pumping line used for the excitation of the ${ }^{2} \mathrm{~F}_{5 / 2}$ level of $\mathrm{Yb}^{3+}$ in the $\mathrm{K}_{2} \mathrm{LaCl}_{5}: 5 \% \mathrm{Pr}^{3+}, 2 \% \mathrm{Yb}^{3+}$ crystal leads to the ${ }^{1} \mathrm{D}_{2}$ and ${ }^{3} \mathrm{P}_{0}$ emissions from the $\mathrm{Pr}^{3+}$ levels. The up-conversion emission depends on the concentration of the $\mathrm{Yb}^{3+}$ ions and the type of the halide matrices. The possible mechanisms of this emission have been already discussed in detail [15], although a definite establishing of the most probable mechanism is still in progress.

\section{Conclusions}

1. The radiative $\mathrm{f}-\mathrm{f}$ transitions probabilities in the single crystals spectra of the $\mathrm{K}_{2} \mathrm{LaCl}_{5}: \mathrm{Pr}^{3+}, \mathrm{K}_{2} \mathrm{PrCl}_{5}$ and $\mathrm{K}_{2} \mathrm{LaCl}_{5}: \mathrm{Pr}^{3+} ; \mathrm{Yb}^{3+}$ as well as in powdered samples were analyzed in the frame of Judd-Ofelt theory.
2. The magnetic dipole transitions $\left({ }^{3} \mathrm{H}_{4} \rightarrow{ }^{3} \mathrm{~F}_{3},{ }^{3} \mathrm{~F}_{4}\right)$ affect strongly the error of the parameters. The Judd-Ofelt parameters were calculated for $\mathrm{K}_{2} \mathrm{LaCl}_{5}: 5 \% \mathrm{Pr}^{3+}$ single crystals with very small errors of the estimation.

3. Unexpectedly high oscillator strength values in the spectra of the $\mathrm{K}_{2} \mathrm{LaCl}_{5}: 5 \% \mathrm{Pr}^{3+}: 2 \% \mathrm{Yb}^{3+}$ in comparison to $\mathrm{K}_{2} \mathrm{LaCl}_{5}: 5 \% \mathrm{Pr}^{3+}$ single crystals were found and can be due to creation some sub-lattices in the structure of codoped systems.

4. The decay times of ${ }^{3} \mathrm{P}_{0}$ as well ${ }^{1} \mathrm{D}_{2}$ level were measured and analyzed as a function of the temperature and concentration.

5. The upconverted emission spectra for $\mathrm{K}_{2} \mathrm{LaCl}_{5}: 5 \%$ $\operatorname{Pr}^{3+}: 2 \% \mathrm{Yb}^{3+}$ and $\mathrm{K}_{2} \mathrm{LaCl}_{5}: 5 \% \mathrm{Pr}^{3+}$ single crystals upon ${ }^{1} \mathrm{D}_{2}$ excitation were presented.

\section{References}

[1] R.T. Wegh, H. Donker, K.D. Oskam, A. Meijerink, Science 283 (1999) 663.

[2] S.C. Krupa, M. Queffelec, J. Alloys Comp. 250 (1997) 287.

[3] P. Dorenbos, J. Lumin. 91 (2000) 91; P. Dorenbos, Phys. Rev. B. 64 (2001) 125117.

[4] A.A. Kaminski, in: Excited States of Transition Elements, World Scientific Publishing Co. Pte. Ltd., Singapore, 1989, p. 669.

[5] L. van Pieterson, M.F. Reid, R.T. Wegh, S. Soverna, A. Meijerink, Phys. Rev. B. 65 (2002) 45113.

[6] J.C. van't Spijker, P. Dorenbos, C.W.E. van Eijk, K. Kramer, H.U. Güdel, J. Lumin. 85 (1999) 1.

[7] A.P. Vink, E. van der Kolk, P. Dorenbos, C.W.E. van Eijk, J. Alloys Comp. 341 (2002) 338.

[8] M. Wenzl, M. Altwein, R. Demirbilek, B. Len, J. Heber, J. Kübler, B. Bleeker, A. Meijerink, J. Alloys Comp. 300-301 (2000) 479.

[9] K. Krämer, H.-U. Güdel, J. Alloys Comp. 207-208 (1994) 128.

[10] A. Ellens, K. Krämer, H.U. Güdel, J. Lumin. 76-77 (1998) 548.

[11] H.P. Andres, K. Krämer, H.U. Güdel, Phys. Rev. B 54 (1996) 3830.

[12] E.V.D. van Loef, P. Dorenbos, C.W.E. van Eijk, K.W. Krämer, H.U.G. üdel, Phys. Rev. B 68 (2003) 45108.

[13] J. Cybińska, J. Hölsä, M. Lastusaari, J. Legendziewicz, G. Meyer, C. Wickleder, Opt. Mater., (in press), doi:10.1016/j.optmat.2005.10.001.

[14] J. Cybińska, J. Hölsä, M. Lastusaari, J. Legendziewicz, G. Meyer, C. Wickleder, J. Alloys Comp. 380 (2004) 27.

[15] J. Cybinska, J. Legendziewicz, G. Boulon, A. Bensalah, G. Meyer, Opt. Mater. 28 (2006) 41.

[16] J. Legendziewicz, J. Cybinska, G. Meyer, Opt. Mater. 24 (2003) 197.

[17] J. Cybinska, J. Sokolnicki, J. Legendziewicz, G. Meyer, J. Alloys Comp. 341 (2002) 115.

[18] G. Meyer, E. Hüttl, Z. Anorg. Allg. Chem. 497 (1983) 191.

[19] G. Meyer, J. Soose, A. Moritz, V. Vitt, Th. Holljes, Z. Anorg. Allg. Chem. 521 (1985) 161.

[20] B.R. Judd, Phys. Rev. 127 (1962) 750; G.S. Ofelt, J. Chem. Phys. 37 (1962) 511;

W.T. Carnall, P.R. Fields, B.G. Wybourne, J. Chem. Phys. 42 (1965) 3747 
W.T. Carnall, P.R. Fields, R. Rajnak, J. Chem. Phys. 49 (1968) 4424.

[21] G. Oczko, J. Legendziewicz, J. Hanuza, J. Gliński, L. Macalik, Acta Phys. Polon. 90 (1996) 431;

J. Legendziewicz, G. Oczko, V. Amirkhanov, R. Wiglusz, V.A. Ovchyhnikov, J. Alloys Comp. 300-301 (2000) 360.

[22] G. Oczko, J. Legendziewicz, W. Stręk, J. Hanuza, in: W. Stręk, W. Ryba-Romanowski, J. Legendziewicz, B. Jeżowska-Trzebiatowska (Eds.), Excited States of Transition Elements, World Scientific Publishing Co. Pte. Ltd., Singapore, 1992, p. 391.
[23] E. Huskowska, P. Porcher, J. Legendziewicz, J. Alloys Comp. 341 (2002) 187.

[24] A. Mondry, K. Bukietyńska, Mol. Phys. 101 (7) (2003) 923.

[25] J. Legendziewicz, Z. Ciunik, P. Gawryszewska, J. Sokolnicki, J. Alloys Comp. 225 (1995) 372.

[26] L. Macalik, J. Hanuza, J. Sokolnicki, J. Legendziewicz, J. Appl. Spectr. 62 (5) (1995) 41.

[27] K. Horchani, J.C. Gâcon, C. Dujardin, N. Garnier, C. Garapon, M. Ferid, M. Trabels-Ayedi, J. Lumin. 94-95 (2001) 69. 